\title{
NFL Draft Prep Players Improve 40-Yard Run Times and Foot-Ground Kinetics
}

Original Research

\author{
G. Monique Mokha ${ }^{1}$, Tobin A. Silver ${ }^{1}$, Pete Bommarito ${ }^{1,2}$ \\ ${ }^{1}$ Nova Southeastern University, Ft. Lauderdale, FL / USA \\ ${ }^{2}$ Bommarito Performance Systems, Davie, FL / USA
}

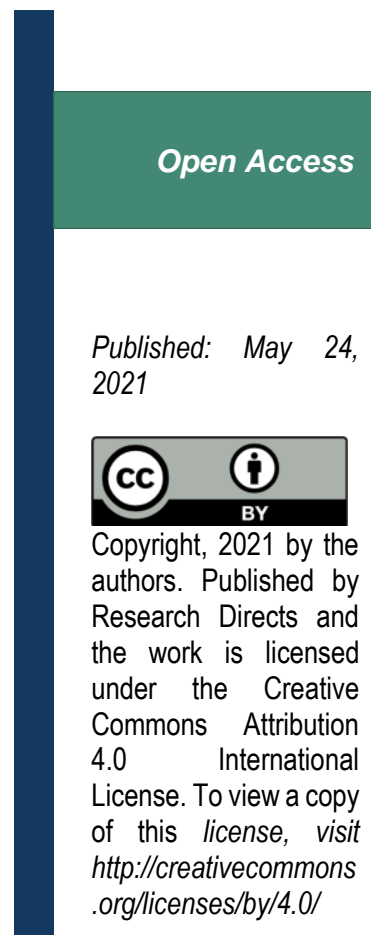

Research Directs in Strength and

Performance: 2021,

Volume 1 (Issue 1): 4

\begin{abstract}
Introduction: Linear speed is a discriminant factor between drafted and undrafted American football players into the National Football League. Linear speed is influenced by foot-ground contact time and the magnitude of vertical ground reaction force. The aim of this study was to determine if foot-ground kinetics during speed running could be modified through participating in a 6 -week NFL draft preparation camp.

Methods: To evaluate foot-ground kinetics, 16 American football players ran on an instrumented treadmill for $5 \mathrm{sec}$ at $6.5 \mathrm{~m} / \mathrm{s}$. Linear speed was measured during a 40 yard $(36.6 \mathrm{~m})$ outdoor run. Pre- and post-camp linear speed times, stance-averaged vertical ground reaction forces (vGRF, $\mathrm{kg} / \mathrm{N}$ ), foot-ground contact time (msec), and vertical impulse $\left(\mathrm{kg} / \mathrm{N}^{*}\right.$ s) were examined using paired $t$-tests, $p<.05$.

Results: Linear speed times significantly improved [(pre, $4.8 \pm 0.2$ vs. post, $4.6 \pm 0.2$ sec), $t(15)=13.8, p<.001)]$, and foot-ground contact time significantly decreased for the right $\operatorname{limb}[($ pre, $177+3.2$ vs. post, $168+2.2 \mathrm{~ms}), t(15)=2.21, p=.043]$. Mean vertical impulse and stance-averaged GRF for both limbs remained unchanged, $p>.05$.

Conclusions: Linear speed and selected foot-ground kinetics are modifiable in NFL draft prep players. Training appears to lower $40 \mathrm{yd}$ run times and foot-ground contact time.
\end{abstract}

Key Words: impulse, football biomechanics, ground reaction forces

Corresponding author: G. Monique Mokha, gm588@nova.edu

\section{Introduction}

Speed running is influenced by foot-ground contact time and the magnitude of vertical ground reaction force $(\mathrm{vGRF})^{1}$. Shorter contact times have been associated with faster running times and greater force application with contact times ranging from 100 to 250 milliseconds (ms), depending upon speed. ${ }^{2,3}$ Peak vertical ground reaction forces (vGRF) can reach as high as five times body weight in sprinters and are a critical contributor to performance capabilities. In short, the runner who applies more force within the least amount of time is the race winner. Impulse is the product of force and time, and impulse largely dictates the runner's ability to accelerate the body from step to step. Large forces applied for long time intervals may increase impulse. However, this requires more energy output than force application over a shorter time interval. Changes in impulse alone will not provide enough feedback to the coach. The coach would need to know if there are changes in how hard (force) and/or how quickly the athlete is hitting the ground. Therefore, it seems judicious to monitor vGRF and foot-ground contact time as well as impulse. 
Foot-ground kinetics may be useful markers to monitor speed running mechanics not just in track sprinters, but in field sport athletes where speed running is integral. American football players seeking to be drafted by the National Football League (NFL) showcase their linear speed running abilities in the 40 yard dash at the annual combine. Drafted players in 2004 and 2005 performed better at the 40 yard dash than nondrafted players indicating the importance of linear speed performance ${ }^{4}$. Select collegiate American football players attend specialized training camps leading up to the NFL combine. A focus of these camps is linear speed mechanics. Mokha and colleagues ${ }^{5}$ investigated running kinetics in a group of players training for the NFL draft and reported stance-averaged vGRF of 1.52-1.59 times body weight and contact times of $170 \mathrm{~ms}$ during a sub-maximal $6.5 \mathrm{~m} / \mathrm{s}$ treadmill run. However, theirs was not an intervention study making training effects in already highly trained athletes illusive. It is unknown if foot-ground kinetics are modifiable in highly skilled American football players. Therefore, the purpose of this study is to investigate the effects of a 6-week training camp on selected foot-ground contact kinetics during a sub-maximal controlled treadmill run in a group of high-level American football players preparing for the NFL draft. We hypothesized that linear speed training would improve performance by lowering $40 \mathrm{yd}$ run times. We also hypothesized training would improve foot-ground kinetics by increasing stand-averaged vGRF and decreasing foot-ground contact time. Given the latter, we hypothesized vertical impulse would remain unchanged. Results will be useful to coaches and athletes for speed development as they can be used to monitor sprint mechanics.

\section{Scientific Methods}

\section{Participants}

Sixteen adult American football players (age, $22.1+1.1 \mathrm{yrs}$; ht, 1.8+0.1 m; mass, $101.0+15.9 \mathrm{~kg}$ ) undergoing specialized training at an off-campus performance center for the NFL draft volunteered for this study. All participants had just completed their collegiate football season, were active players training 5-6x per week, and were 16 of the 330 players invited to the NFL combine. The study was approved by the University's Institutional Review Board, conducted in accordance with the ethical standards of the Helsinki Declaration and subjects provided written informed consent.

\section{Protocol}

All data were collected over three days at the start of week 1 and at the end of week 6 with each athlete reporting to one testing session in the laboratory and one on the training field. This study was part of a larger study monitoring pre-post changes in vertical and drop jumping, sprinting mechanics, and body composition over the duration of the 6-week training camp. Camp was divided into three microcycles that included drill specificity training, player position specificity training, resistance training and recovery-based movement (e.g., pool, soft tissue massage). Table 1 presents specific drills used by the coaches to improve linear speed. Figure 1 depicts sample drills defined in Table 1.

Table 1. Linear Speed Drills* Used During the 6-week Training Camp.

\begin{tabular}{|c|c|}
\hline & Description \\
\hline $\begin{array}{l}\text { Ankling to butt kick } \\
\text { series }\end{array}$ & $\begin{array}{l}\text { Push toe to top of sneaker; lock ankle; hands break waste/hip; tuck head; move } \\
\text { forward } 5 \mathrm{yd} \text {. }(4.6 \mathrm{~m}) \text {; progress to additional } 5 \mathrm{yd}(4.6 \mathrm{~m}) \text { spent emphasizing heel to } \\
\text { buttocks }\end{array}$ \\
\hline A-run series & $10 \mathrm{yd}(9.1 \mathrm{~m})$ build-up jog then ankling to butt kicking series \\
\hline Moving claw series & $\begin{array}{l}\text { Push toe to top of sneaker; butt kick then clear knee; relax quadriceps and attack } \\
\text { ground; gradually add rapid 1-2 arm motion }\end{array}$ \\
\hline Prowler (sled) sprint & $\begin{array}{l}\text { Feet together; push toe to top of sneaker; lock ankle; knee-up piston action; knees in } \\
\text { front of body; no butt kick; then accelerate forward pushing sled; sled weight } \\
\text { increases over sessions }\end{array}$ \\
\hline $\begin{array}{l}\text { Linear acceleration } \\
\text { wall drill }\end{array}$ & $\begin{array}{l}45 \text { degree lean against wall/fence/sled; feet together; push toe to top of sneaker; lift } \\
\text { one knee then drive straight down; switch legs slowly then rapidly increase steps }\end{array}$ \\
\hline Assisted sprint series & $\begin{array}{l}\text { Pulley system between athlete and coach where coach pulls athlete forward after run } \\
\text { begins }\end{array}$ \\
\hline 3-part start technique & Drill to teach set up for the 3-point start required by NFL \\
\hline Kneeling arm drill & $\begin{array}{l}\text { Half kneeling position; head down; long, pendulum arm swing progressing to arm } \\
\text { swing at jog pace then run pace then sprint pace }\end{array}$ \\
\hline
\end{tabular}

*Note: Complete explanations and demonstrations found at https://bbcom.me/36Kgq6P. 


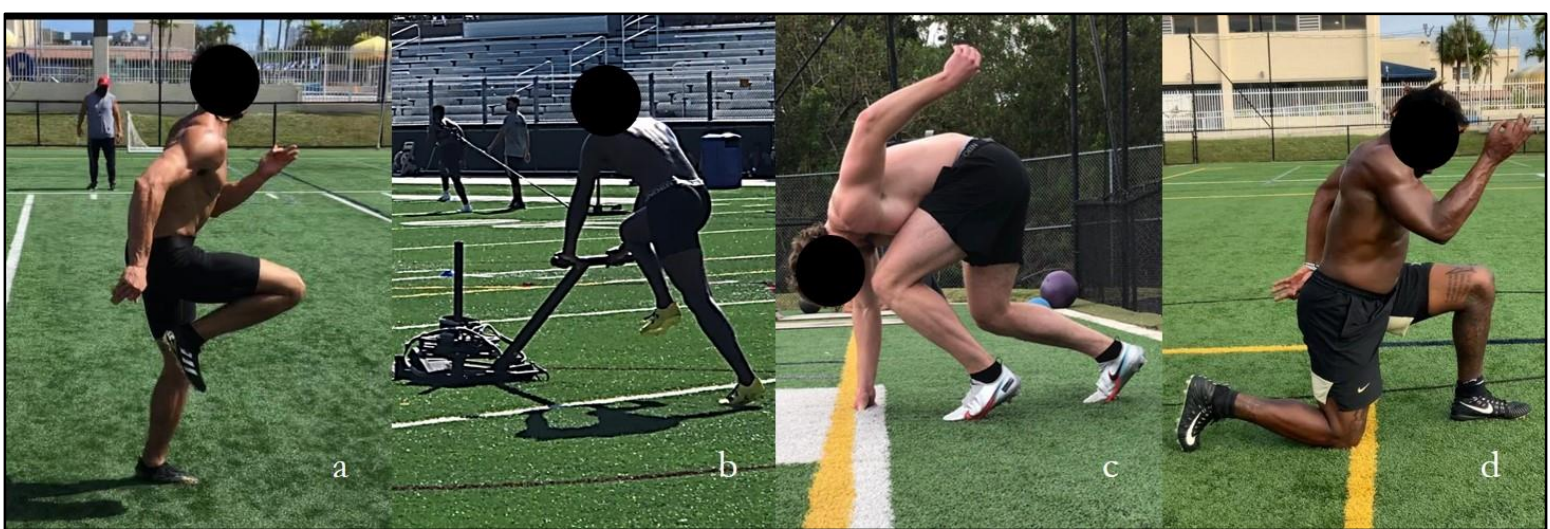

Fig. 1. Example linear speed drills from Table 1: (a) ankling to butt kick series, (b) linear acceleration wall drill, (c) 3part start technique, and (d) kneeling arm drill.

All participants underwent a standardized 25 min. warm-up for both run tests that consisted of dynamic stretching, muscle readiness and reactivity exercises. The $40 \mathrm{yd}$ run was tested on an outdoor runway using Smartspeed Pro timing gates (Fusion Sport, Boulder, CO, USA). The best (lowest) time of two trials was recorded. The laboratory running trial took place on an instrumented split belt treadmill (Bertec, Columbus, OH, USA) with participants running on one side. Participants began the trial holding onto the handrail fixed at chest height of the treadmill walking at $1 \mathrm{~m} / \mathrm{s}$. Then the treadmill was increased $1 \mathrm{~m} / \mathrm{s}$ in one second increments until $6.5 \mathrm{~m} / \mathrm{s}$ was reached, which was the maximum allowed by the treadmill. Participants were instructed to release their grip when they were comfortable, and vGRFs and contact times were collected at $1000 \mathrm{~Hz}$ for a period of $5 \mathrm{sec}$. See Figure 2. This time was selected to mimic most 40 yard $(36.6 \mathrm{~m})$ run duration at the NFL combine. Subjects then transferred their weight to the non-moving belt, and the treadmill belt was decelerated to a stop. Only one running trial was collected. All trials were post-processed with a low pass Butterworth filter with a cut-off frequency of $40 \mathrm{~Hz}$. Data presented represent the average of three consecutive steps for each leg. The variables of interest were defined as follows:

Stance-averaged ground reaction force ( $v G R F)$ was the average vertical ground reaction force normalized to body weight (BW) during the step. Stance-averaged vGRF was selected over peak vGRF because it is less subject to intraindividual variance $^{6}$.

Vertical impulse was the area under the curve of the vGRF. Vertical impulse was calculated in a custom MATLAB $\mathbb{R}$ program (MathWorks, Natlik, MA, USA) as the integral of the force-time curve using the trapezoid method, $\int v G R F d t$ 7.

Ground contact time was a measure of continuous foot-ground contact time in milliseconds (ms) with the treadmill when the vGRF exceeded $40 \mathrm{~N}$.

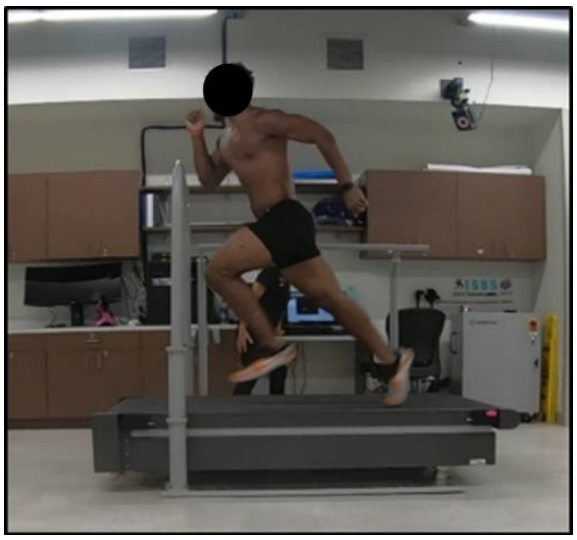

Fig. 2. Participant running on instrumented treadmill. 
Statistical Analysis

Training effects were assessed by examining significant changes in pre- and post-test $40 \mathrm{yd}$ run times, stance-averaged vGRFs, foot-ground contact times, and vertical impulse for the group using dependent $t$-tests. Statistics Package for Social Sciences (ver. 26; IBM Corporation, New York, NY, USA) was used for the analyses. Significance was considered at $p<.05$.

\section{Results}

Table 2 presents the means and standard deviations of the $40 \mathrm{yd}$ run times and foot-ground kinetics for each limb. Foot-ground contact time decreased for both limbs with statistical significance on the right $[t(15)=2.21, p=.043]$. Stance-averaged vGRFs increased for both limbs after training but the increases were not statistically significant. Figure 2 represents right limb vGRF and impulse for a sample participant pre- and post-training.

Table 2. Pre- and post-test run times, and right and left foot-ground contact times and forces.

\begin{tabular}{|c|c|c|c|}
\hline & $\begin{array}{l}\text { pre } \\
(\mathrm{N}=16)\end{array}$ & $\begin{array}{l}\text { post } \\
(\mathrm{N}=16)\end{array}$ & $p$ value \\
\hline 40 yd run time (s) & $4.8 \pm 0.2$ & $4.6 \pm 0.2$ & $<.001 *$ \\
\hline $\begin{array}{l}\text { Right foot-ground contact } \\
\text { time (ms) }\end{array}$ & $177 \pm 3.2$ & $168 \pm 2.2$ & $.043^{*}$ \\
\hline $\begin{array}{l}\text { left foot-ground contact } \\
\text { time (ms) }\end{array}$ & $174 \pm 3.2$ & $166 \pm 2.1$ & .125 \\
\hline $\begin{array}{l}\text { Right ave. foot-ground } \\
\text { vertical force (BW) }\end{array}$ & $1.5 \pm 0.3$ & $1.6 \pm 0.1$ & .131 \\
\hline $\begin{array}{l}\text { Left ave. foot-ground } \\
\text { vertical force (BW) }\end{array}$ & $1.5 \pm 0.3$ & $1.7 \pm 0.2$ & .053 \\
\hline $\begin{array}{l}\text { Left vertical impulse } \\
(\mathrm{kg} / \mathrm{n} * \mathrm{~s})\end{array}$ & $29.0 \pm 5.1$ & $29.0 \pm 4.0$ & .978 \\
\hline $\begin{array}{l}\text { Right vertical impulse } \\
(\mathrm{kg} / \mathrm{n} * \mathrm{~s})\end{array}$ & $28.8 \pm 3.9$ & $29.1 \pm 3.7$ & .792 \\
\hline
\end{tabular}

Data are Means \pm SD

$*$ Significantly decreased foot-ground contact time at post-test, $p<.05$.

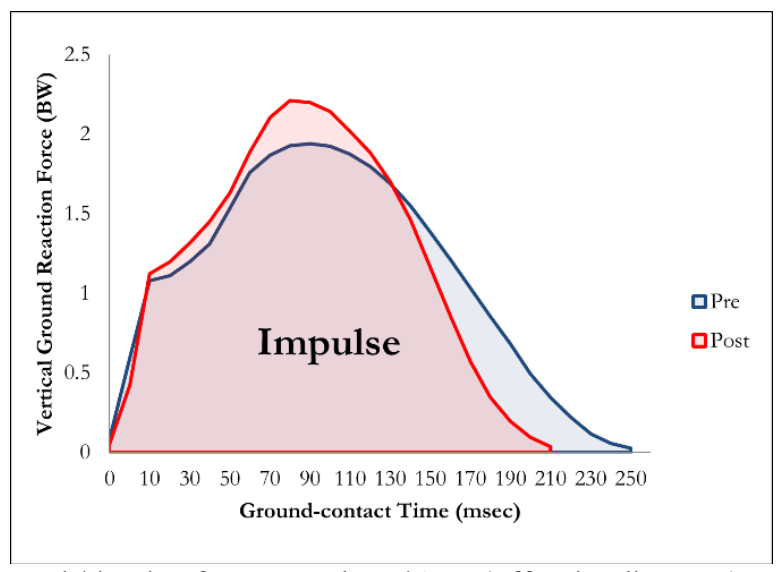

Figure 2. Right limb foot-ground kinetics for a sample subject (offensive lineman). Note the increase in force and decrease in contact time.

\section{Discussion}

This study sought to monitor the changes in foot-ground running kinetics and performance of high-level American football players before and after a specialized NFL draft preparation camp. While testing occurred during a submaximal run rather than during a maximum velocity sprint, we observed changes in vertical foot-ground kinetics that are meaningful. Results indicate that vertical foot-ground contact force and contact time are modifiable in high-level athletes. The contact time was reduced for both limbs and this was statistically significant on the right. Shorter contact 
times are associated with faster running speeds in sprinters ${ }^{2,3}$ so this change was interpreted as a factor that could positively contribute to performance. Contact times ranged from 140 to $250 \mathrm{~ms}$. These are comparable to published times from sprinters ${ }^{2,3}$ and American football players ${ }^{5}$. Maćkała and Fostiak ${ }^{8}$ documented decreases in foot-ground contact time from 138 to $133 \mathrm{~ms}$ during a $20 \mathrm{~m}$ run in sprinters from a 2-week plyometric intervention program. Although not statistically significant, stance-averaged vGRFs increased from pre- to post-testing in the current study of select American football players. Higher vGRFs are also associated with faster running speeds in sprinters ${ }^{9,10}$. The combined findings of reduced foot-ground contact times and increased vGRFs suggest improved running mechanics and linear speed. Indeed, 40 yard $(36.6 \mathrm{~m})$ run times assessed at the start and end of camp by the coach did improve in this group (pre, $4.8 \pm 0.2$ vs. post, $4.6 \pm 0.2 \mathrm{sec}$ ). Drills such as ankling, A-runs, prowler sprints, and assisted sprinting were progressively incorporated into the participants' 6-week training program (see Table 1). These drills are designed to improve an athlete's ability to strike the ground forcefully relative to body weight and to do so over an exceptionally short time period. Impulse is the product of the ground reaction forces and the contact time duration. While large vGRF are integral to successful sprint performance, the time-dependent nature of sprinting prevents athletes from fully expressing their maximum force capabilities ${ }^{11}$. This makes the rate of force development important in allowing athletes to develop high vGRF relative to body weight during each step permitting the production of large impulses given the contact time constraints ${ }^{12}$. Impulse describes the area under the vGRF curve. Figure 2 illustrates changes in impulse from the pre- to the post-test for a sample player in this study. DeWeese and colleagues ${ }^{12}$ suggest that practitioners can describe the shape and magnitude of an athlete's sprint force-time profile similarly to phase analyses in a countermovement jump. Monitoring impulse in this fashion provides an objective means for how the athlete is imparting force to the ground. In this study, impulse did not significantly change for the group. Although increased vGRF coupled with decreased contact time occurred, impulse remained the same or decreased for six subjects. This finding is interesting. One could suggest the athletes are improving force production with decreased contact time to maintain pre impulse conditions. This may relate to improved running economy, specifically while maintaining the same speed as previously tested. Maintaining impulse for the same speed while improving force production in a decreased amount of time could suggest improved performance at that speed. This suggests a positive transfer effect to the field where improved 40 yard $(36.6 \mathrm{~m})$ run times were found in this group, where there is no belt length or speed limitations opposed to the environment where one must maintain such control.

Intervention studies involving running kinetics are extremely limited. In a study involving 5,000 m distance runners, Sato and Mokha ${ }^{13}$ improved running times but failed to significantly change active and peak vGRFs after six weeks of core training. Participants in the current study were not only working on linear speed, but other aspects of football combine performance to enhance the vertical and broad jumps, and agility run drills. Yet, improvements were made in ground-contact kinetics. Additionally, participants in this study were part of the select 330 players in the United States receiving invitations to the NFL combine annually. Combine performance influences draft status. Fifteen of 16 participants in this study were drafted into the NFL, and one went in the first round. Thus, the participants in this study were highly skilled American football players so even small kinetic improvements may be meaningful for performance. However, this study is not without limitations. The running trials were controlled on a treadmill at 6.5 $\mathrm{m} / \mathrm{s}$ which is not maximum velocity for these athletes nor did it allow for assessment of how the athlete transitions from the drive to the transition phase or the transition to top speed phase. However, since vGRF increase as speed increases, standardizing the treadmill speed allowed vGRF changes to be isolated. This study is also limited in that it only addressed vertical kinetics. Forces applied in the horizontal direction, especially propulsive forces influence linear speed and acceleration ${ }^{14,15}$ and if examined would add value to the current study's results.

This study resulted in sport-specific findings during a sub-maximal controlled running trial resulting from draft preparation of high-level American football players. Results indicate that even in highly trained players, speed running mechanics may be improved through specialized training camps. Specifically, foot-ground contact time may decrease and relative vertical forces may increase. While it cannot be assumed these changes alone would be enough to improve the participants' linear speed in the 40 yard $(36.6 \mathrm{~m})$ run, they shed light on how foot-ground kinetics may be modified and monitored for performance.

\section{Conclusions}

Linear speed and select foot-ground kinetics are modifiable in NFL draft prep players. Training appears to lower 40 yd run times and foot-ground contact time. 


\section{Acknowledgements}

The authors wish to thank coach Josh Walters from Bommarito Performance Systems for administering the standardized warm-up to all players at both the pre- and post-testing sessions.

\section{Conflict of Interest}

The authors have no conflicts of interest to declare.

\section{References}

1. Weyand PG. Force, motion, speed: A grounded perspective on human running performance. In: International Society of Biomechanics in Sports Conference Proceedings (eds W Potthast, A Niehoff, D Sina), Cologne, Germany, 14-18 June 2017, paper no. 289. Marquette: ISBS.

2. Paavolainen L, Nummela A, Rusko H, Häkkinen K. Neuromuscular characteristics and fatigue during $10 \mathrm{~km}$ running. Int J Sports Med. 1999; 20(8):516-521.

3. Weyand PG, Sternlight DB, Bellizzi M.J and Wright S. Faster top running speeds are achieved with greater ground forces not more rapid leg movements. J Appl Physiol. 2000; 89(5):1991-1999.

4. Sierer SP, Battaglini CL, Mihalik JP, Shields EW, Tomasini NT. The National Football League Combine: Performance differences between drafted and nondrafted players entering the 2004 and 2005 drafts. J Strength Cond Res. 2008; 22(1):6-12.

5. Mokha M, Jiannine L, Bommarito P, Antonio J. Relationship of body mass and bilateral running gait parameters in elite American football players. In: International Society of Biomechanics in Sports Conferences Proceedings (eds M Walsh, M Stutz and S Breen), Oxford, USA, 22-26 July 2019, paper no. 45. Marquette: ISBS.

6. Munro CF, Miller DI, Fuglevand AJ. Ground reaction forces in running: A reexamination. J Biomech. 1987; 29(2):147-155.

7. Tongen A, Wunderlich RE. Biomechanics of running and walking. In: Gallian JA (ed) Mathematics and sports. Washington DC: Mathematical Association of America; 2010, pp. 315-327.

8. Maćkała K, Fostiak M. Acute effects of plyometric intervention-Performance improvement and related changes in sprinting gait variability. J Strength Cond Res. 2015; 29(7):1956-1965.

9. Hunter JP, Marshall RN, McNair PJ. Relationships between ground reaction force impulse and kinematics of sprint-running acceleration. J Appl Biomech. 2005; 21:31-43.

10. Weyand PG, Sandell RF, Prime DNL, Bundle MW. The biological limits to running speed are imposed from the ground up. J Appl Physiol. 2010; 108, 950-961.

11. Seitz LB, Reys A, Tran TT, Saez de Villarreal E and Haff GG. Increases in lower-body strength transfer positively to sprint performance: A systematic review with meta-analysis. Sports Med. 2014; 44(12):1693-1702.

12. DeWeese BH, Wagle JP, Williams J, Sams MI. Speed play. Techniques for Track and Field Quarterly. 2019; 12(4):8-

24.

13. Sato K, Mokha M. Does cores strength training influence running kinetics, lower-extremity stability, and performance in runners? J Strength Cond Res. 2009; 23(1): 133-140.

14. Morin JB, Slawinski J, Dorel S, Couturier A, Samozino P, Brughelli M, Rabita G. Acceleration capability in elite sprinters and ground impulse: Push more, brake less?. J Biomech. 2015; 48(12):3149-54.

15. Kawamori N, Nosaka K, Newton R. Relationships between ground reaction impulse and sprint acceleration performance in team sport athletes. J Strength Cond Res. 2013; 27(3): 568-573. doi: 10.1519/JSC.0b013e318257805a 